\title{
Sustainability economics, ontology and the capability approach
}

\author{
Nuno Martins* \\ Portuguese Catholic University, Faculty of Economics and Management, Rua Diogo Botelho 1327, 4169-005 Porto, Portugal
}

\section{A R T I C L E I N F O}

\section{Article history:}

Received 6 July 2011

Received in revised form 20 September 2011

Accepted 29 September 2011

Available online $\mathrm{xxxx}$

\section{Keywords:}

Capabilities

Ontology

Sustainability

Freedom

Uncertainty

\begin{abstract}
A B S T R A C T
The relationship between sustainability economics and the capability approach has recently been explored. Here I shall discuss this relationship, and argue that a study of the ontology underlying the capability approach can help us to see more clearly the interconnections between sustainability economics and the capability approach. In particular, the interpretations of the capability approach as an ontological exercise, which have recently emerged in the literature, enable us to have a better understanding of the essential categories used in the capability approach, and to establish a clearer connection between the capability approach and sustainability economics.
\end{abstract}

(c) 2011 Elsevier B.V. All rights reserved.

\section{Introduction}

Jérôme Ballet, Damien Bazin, Jean-Luc Dubois and François-Regis Mahieu (2011) have recently explored the relationship between sustainability economics and the capability approach, drawing upon the contribution to sustainability economics of Stefan Baumgärtner and Martin Quaas (2010). Here I shall extend this discussion, and argue that a fruitful way to continue this debate is to take into account an issue addressed by Baumgärtner and Quaas (2010), which is absent from the discussion undertaken by Ballet, Bazin, Dubois and Mahieu (2011), namely the topic of ontology. Once we understand the role that ontological categories such as "internal relation" and "open system" play within sustainability economics and the capability approach, we can then establish a clearer connection between the capability approach, and sustainability economics, as defined by Baumgärtner and Quaas (2010).

\section{The Capability Approach And Sustainability Economics}

Baumgärtner and Quaas (2010) engage in an important analysis of what sustainability economics is. In so doing, Baumgärtner and Quaas (2010, p. 445) study various aspects of sustainability economics, such as its "normative foundation, aims, subject matter, ontology, and genuine research agenda". Ballet, Bazin, Dubois and Mahieu (2011, p.1)

\footnotetext{
* Tel.: + 351917729069 .

E-mail address: nmartins@porto.ucp.pt.
}

point out the following definition of sustainability economics put forward by Baumgärtner and Quaas (2010):

"Sustainability economics is ethically founded in the idea of efficiency, that is non-wastefulness, in the use of scarce resources for achieving the two normative goals of (i) the satisfaction of individuals' needs and wants, and (ii) justice, including justice between humans of present and future generations, and justice towards Nature, within the setting of human-nature relationships over the long-term and inherently uncertain future." (Baumgärtner and Quaas, 2010, p.447, cited also in Ballet, Bazin, Dubois and Mahieu, 2011, p.1)

On the first issue pointed out in this definition, concerning the satisfaction of human needs and wants, Ballet, Bazin, Dubois and Mahieu (2011, p.1) note how the capability approach can help us to "go beyond the usual normative framework of individual resource allocation". In fact, Amartya Sen (1992) argues that resources are only a means to well-being, not the end we are seeking. Furthermore, Sen notes that different human beings, placed in different situations, will obtain different levels of well-being when endowed with the same level of resources.

Thus, as Ballet, Bazin, Dubois and Mahieu (2011, p.1) note, the capability approach takes into account the "factors that block the conversion of resources into real opportunities, and which consequently reduce the field of opportunities", where these factors "can be personal (disabilities, etc.), social (discrimination, exclusion, etc.), or environmental (droughts, etc.)." - see also Wiebke Kuklys (2005) or Ingrid Robeyns (2005) on conversion factors.

The differences between human beings are also captured by the utilitarian framework of neoclassical economics, for different human beings might have different utility functions, which reflect different 
desires. However, Sen (1992) notes that utilities reflect the person's mental metric, not underlying needs that are essential given the nature of human beings. Thus, it is necessary to focus on both needs and desires, and not only on desires, as the utilitarian framework often does.

Furthermore, to focus only on needs and desires is to focus only on achievements. But, Sen (1992) argues, freedom to achieve is also fundamental. Ballet, Bazin, Dubois and Mahieu (2011, p.1) note how the capability approach "enables us to go beyond the normative economic goal, i.e. the satisfaction of needs and desires." The satisfaction of needs and desires remains a legitimate economic goal. But human well-being, according to Sen, does not consist only in the satisfaction of needs and desires, since it also includes the freedom to choose.

Sen (1992) defines well-being in terms of human functionings, where a human functioning is what a person is or does. Sen (1992) uses the term capabilities to denote the potential functionings we can achieve. Sen (1992, p. 60) distinguishes between well-being achievement and well-being freedom. While well-being achievement depends upon the functionings we achieve, well-being freedom depends upon the capabilities, or potential functionings, that human beings possess, and so we must consider not only achieved functionings, but also the freedom to achieve. To focus on capabilities rather than on resources can lead us to a very different assessment of human well-being, also in the context of sustainability economics, not only because the relation between resources and different human beings is taken into account, but also because freedom to achieve is also taken into account.

Freedom of choice, concerning the capability space, is relevant not only for the first aspect pointed out by Baumgärtner and Quaas (2010) in their definition of sustainability economics - concerning the satisfaction of individuals' needs and wants, which can now be seen in broader terms, as the expansion of the individuals' capability space - but also for the second aspect pointed out by Baumgärtner and Quaas (2010) in their definition of sustainability economics, namely the issue of justice between generations and towards Nature.

Effectively, the future generations may came to value outcomes in a different way than we do, so even if we provide them with a future which, according to our standards, provides the outcomes which we value most, those may not be the outcomes that the future generations value most, and hence freedom of choice is fundamental.

If future generations may have different preferences and values than our own, (and if even our own preferences and values may change with time), then freedom of choice, or a broader capability space, must be provided, so that future generations (or maybe our own generation) can have the capability to achieve the outcomes they will value (whatever they may be), rather than the outcomes we presently value.

\section{Utilitarianism And The Capability Approach}

The role of future preferences, within a conceptual framework compatible with utilitarianism, was emphasized by Henry Sidgwick (1874), one of the founders of the Cambridge 'welfare' tradition, which influenced Sen - this issue is explained in more detail in Martins (2009). Future preferences have also been discussed more recently by Kenneth Arrow (1995) and Pattanaik and Xu (1998).

Sidgwick adopted a broad ethical framework, which emphasized freedom of choice due to the possibility of change of preferences, while making this approach compatible with a utilitarian framework. But it is important to note that there are nevertheless various versions of utilitarianism, and some are more distant from Sen's perspective than others. While Jeremy Bentham provided an analysis of pleasure and pain where subjective feelings could be reduced to a common subjective metric, John Stuart Mill emphasized the fact that there are different kinds of pleasure, without necessarily reducing them to a unidimensional conception.
The perspective of Stuart Mill, which also influenced Sidgwick, is more akin to Adam Smith's or Karl Marx's multidimensional conception of well-being, which Sen (2009) recovers, than to the unidimensional conception of well-being that underpins mainstream economics - see also Mozaffar Quizilbash (2008) on the relationship between Sen's conception and the utilitarianism of Stuart Mill. Sen's criticism is aimed especially at the utilitarian approaches which follow Bentham, but not at Stuart Mill or Sidgwick.

There is an important similarity between the contribution of Sen, and of authors like Smith and Sidgwick. This similarity is that these authors attempted to provide a contribution which would include, rather than exclude, other ethical perspectives. Smith (2002) divides moral systems depending on whether they make virtue consist in propriety, prudence or benevolence. Sidgwick (1874) also divides moral systems into egoism, altruism and intuitionism. But both Smith and Sidgwick attempt to find common ground between these competing systems, just like Sen (2009) attempts to find a common ground between various approaches.

From utilitarianism, Sen takes the emphasis on consequences, and on how different human beings are affected in different ways. From John Rawls's (1971) perspective, Sen takes the emphasis on opportunities, and on a more objective perspective. The capability approach is then developed as a perspective that focuses on the diversity of human beings and on consequences (like utilitarianism), but using objective human functionings (instead of subjective utility) as a measure of well-being, while also emphasizing the potential to achieve. Sen's critique of utilitarianism or resource based views must be seen as a constructive dialogue, following the traditions of Smith and Sidgwick.

\section{The Critical Realist Relational Ontology And The Capability Approach}

However, there is an important way in which Sen's contribution differs from the contributions of authors like Immanuel Kant or Rawls, while following Smith, Mill and Marx, amongst others. Kant and Rawls were essentially concerned with prescriptive a criterion (or "method", in Sidgwick's terms) for ethical decisions. Sen, on the other hand, is concerned with the description of the space in which to assess human well-being.

In fact, the capability approach is not a complete ethical theory. For example, while utilitarianism provides a space in which to assess well-being (the space of utility) and a criterion to choose between possible scenarios (the maximization of the sum of individual utilities), the capability approach focuses only on the space. That is, it focuses on the descriptive element (the space in which to assess well-being) rather than on the prescriptive element (the criterion).

Effectively, the capability approach can be best interpreted as an exercise in ontological description. Ontology is a study of the nature of reality. While a scientific theory explains empirical observations, identifying the causal mechanisms or structures which cause events, ontology is concerned with the nature of the entities posited in scientific theories. For example, if a scientific theory would attempt to explain the causal mechanisms through which the supply of money may influence prices, an ontological enquiry would ask "what is money" or "what is a price (or what is value)".

Ontology is a topic also addressed by Baumgärtner and Quaas (2010), in their discussion of the ontology of sustainability economics. In Section 4, which is on the "Ontology of Sustainability Economics" (Baumgärtner and Quaas, 2010: 447), they pose ontological questions such as "What is the Human Being?", "What is Nature?" or "What is the Economy?" (Baumgärtner and Quaas, 2010: 448). The capability approach can be seen as an answer to one specific ontological question of this sort, namely the question of "what is human well-being?" Notions such as human functionings and human capabilities are developed by Sen as an answer to these ontological questions: well-being achievement 
is characterized in terms of human functionings, and well-being freedom is seen in terms of potential functionings, or capabilities.

Recent contributions have highlighted the ontological nature of the capability approach, and how the capability approach is particularly compatible with a critical realist ontology, in which entities are constituted by the very relations in which they stand - see Nuno Martins (2006, 2007), Matthew Smith and Caroline Seward (2009) and Ilse Oosterlaken (2011), who interpret the capability approach in terms of a critical realist ontology; critical realism, in turn, has been developed by authors like Margaret Archer, Roy Bhaskar, Andrew Collier, Tony Lawson and Alan Norrie (1998).

This focus on a critical realist ontology can shed much light on the connections between sustainability economics and the capability approach, because of the relational ontology it provides. The relationship to Nature, and to other human beings, are central elements pointed out by Baumgärtner and Quaas (2010). When Baumgärtner and Quaas (2010, p. 448) discuss the ontological question of "What is the Human being", they consider relational aspects such as "How and to what extent is the human being as a biological being determined by, and dependent upon, nature (homo biologicus)?", or "How and to what extent is a human individual determined by, and dependent upon, social relationships (homo sociologicus)?"

The interpretation of the capability approach in terms of a critical realist relational ontology can be fruitfully linked to these ontological questions raised by Baumgärtner and Quaas (2010). According to the critical realist relational ontology, human beings are constituted by their relationships to Nature and society. This means that human beings, Nature and society are internally related. Tony Lawson defines internal relations in the following way:

"Aspects or items are said to be internally related when they are what they are, or can do what they do, in virtue of the relation to others in which they stand. In other words, internally related features are, in part, constituted by such relations." (Lawson, 2007b, p. 257)

However, according to critical realism, human individuals are not completely determined by the relationships in which they stand. Rather, human individuals and social structures are ontologically distinct entities, where neither can be reduced to the other.

In the critical realist relational ontology, social and technological structures are the conditions of possibility for human activity, which are transformed and reproduced by human activity - on the role of technology within a critical realist perspective, see also Lawson (2007a, 2010), or Oosterlaken (2011). Social and technological structures facilitate and constrain human agency, but do not determine the latter.

Baumgärtner and Quaas (2010, p. 448), when posing several ontological questions, also ask "How and to what extent is a human being free?", which is a relevant question to ask once we consider human beings to be (at least partly) constituted by their relations to Nature and society. The answer that the critical realist ontology provides is that the freedom of the human being depends upon the social and technological structures, which are permanently reproduced and transformed by human agency.

But because human agents and social structures are seen as ontologically distinct entities within critical realism, we can acknowledge the causal influence of social structures on human agents, and of human agents on social and technological structures, without presupposing that human agency is determined by social and technological structures. Human agents are conditioned, but not determined, by social and technological structures, which shape the boundaries of human freedom. The capability approach provides an answer to this ontological question posed by Baumgärtner and Quaas (2010, p. 448) too, of "How and to what extent is a human being free?", by focusing on the capability space, which can be seen as shaped by social and technological structures - Martins (2006, 2007), Smith and Seward (2009), Oosterlaken (2011).

There is often some reluctance concerning the acceptance of the causal role of social structures, and thus Ortrud Leßmann (2011, p.19) writes that "to keep social conditions as motives for individual behaviour in mind, seems to match [sic] ethical individualism of the CA [Capability Approach] much better than oversocialized approaches such as social ontological ones (e.g. Martins, 2007, 2009)".

However, as Ingrid Robeyns (2005, p. 107) argues, "we must distinguish between ethical individualism on the one hand, and methodological and ontological individualism on the other". Robeyns (2005, p. 108) also argues that "a commitment to ethical individualism is not incompatible with an ontology that recognizes the connections between people, their social relations, and their social embedment" and concludes that " $\mathrm{t}]$ he capability approach embraces ethical individualism, but does not rely on ontological individualism."

In fact, unless individuals are taken to be completely determined by social structures, there is no reason why the recognition of the causal role of social relationships must lead to an oversocialized approach, as Leßmann (2011, p.19) argues. As Sen writes:

"When someone thinks and chooses and does something, it is, for sure, that person - and not someone else - who is doing these things. But it would be hard to understand why and how he or she undertakes these activities without some comprehension of his or her societal relations.

The basic issue was put with admirably clarity by Karl Marx (1959: 104) more than a century and a half ago: "What is to be avoided above all is the re-establishing of "Society" as an abstraction vis-à-vis the individual'. The presence of individuals who think, choose and act - a manifest reality in the world - does not make an approach methodologically individualist. It is the illegitimate invoking of any presumption of independence of the thoughts and actions of persons from the society around them that would bring the feared beast into the living room." (Sen, 2009, p. 245)

The role of social relationships is thus central in influencing the "thoughts and actions of persons". The ontological study of the relationships of human agents to nature and to society which Baumgärtner and Quaas (2010, p. 448) discuss is an issue which can be fruitfully linked to the recent explorations of the relations between the critical realist relational ontology and the capability approach.

\section{Uncertainty And Ontology}

In the interpretation of the capability approach in terms of the critical realist ontology, we find a conception where capabilities are seen as causal powers, which emerge within a relational reality Martins (2006, 2007), Smith and Seward (2009), Oosterlaken (2011). In this conception, capabilities have the power to provide well-being, but whether such a potential is exercised or not depends on context, or the existing set of relationships. In the literature on the capability approach, this context is usually termed as the "conversion factors" - see Kuklys (2005), Robeyns (2005) or Smith and Seward (2009). But because capabilities are causal powers that may, or may not, be exercised, there is always uncertainty concerning future outcomes.

Within this conception, reality is seen as an open system, which is a system in which constant conjunctions of the form "if event $X$ then event Y" do not always occur - see also Lawson (2007b). It is because social reality and nature, are open systems, that uncertainty is always present. In fact, it is not only social reality, but also natural reality, that constitutes an open system. Thus, even natural sciences have to artificially construct closed systems in laboratory experiments, in which constant conjunctions of the form "if event X then event $Y$ " occur, when engaging in exact modeling - see Archer, Bhaskar, Collier, Lawson and Norrie (1998).

Baumgärtner and Quaas (2010, p.447) point out, in their definition of sustainability economics, "justice toward Nature, within the setting of human-nature relationships over the long-term and inherently uncertain future." The fact that the future is uncertain means again that the capability space of future generations must be a broad one, since 
they may have to deal with problems which we never imagined. Uncertainty exists thus not only concerning what will be our future preferences and values, but also concerning Nature. In fact, uncertainty is relevant not only regarding future outcomes, but also regarding very immediate and present outcomes, and how we assess them.

The fact that uncertainty exists, concerning not only Nature, but concerning our preferences and values, means that we need a framework which takes openness of outcomes into account. Capabilities, as causal powers that may or may not be exercised, are constitutive elements of such an open system. When the capability approach is interpreted in terms of a critical realist ontology, where capabilities are seen as causal powers, the relationships between the capability approach and sustainability economics, as systematized by Baumgärtner and Quaas (2010), can be seen in a clearer light, concerning not only relations to Nature and social relationships, but also the open nature of natural and social reality.

Ballet, Bazin, Dubois and Mahieu (2011) identify however two shortcomings in the capability approach. First, as Flávio Comim (2003) explains, the capability approach "is based on a static analysis, and because of this it ignores a number of dynamic questions, not all of which are related to the analysis of human/environment systems." (Ballet, Bazin, Dubois and Mahieu, 2011, p. 3). The second shortcoming is that the capability approach "is an approach that does not explicitly take uncertainty into account" (Ballet, Bazin, Dubois and Mahieu, 2011, p. 3).

However, if we see the capability approach as an ontological exercise, which must be supplemented by further substantive theorizing, we see that to provide a substantive treatment of dynamic problems or uncertainty is beyond the scope of the capability approach. The capability approach provides an ontological framework for the description of human well-being where dynamics and uncertainty can be accommodated, since it presupposes a processual, internally related, and open reality - see Martins (2006, 2007), Smith and Seward (2009), and Oosterlaken (2011). But it does not engage in a substantive treatment of dynamic issues or uncertainty, since such an endeavor is beyond the scope of an ontological exercise. To do so, further substantive work is necessary.

In fact, it is because the capability approach is essentially an ontological exercise that when we look at more substantive issues, the capability approach will be found to be vague and theoretically underspecified - see also Anand, Hunter, and Smith (2005) on the theoretical under-specification of the capability approach. The capability approach, as an answer to the ontological question of "what is human well-being?", must be supplemented with more substantive analysis.

In this regard, sustainability economics and the capability approach can be fruitfully complementary. If the capability approach provides only an answer to the ontological question of "what is human well-being", sustainability economics addresses the dynamic issues and uncertainty which must be taken into account when engaging in more substantive questions.

\section{Conclusion}

Ballet, Bazin, Dubois and Mahieu (2011, p.1) discuss how the capability approach can be a foundation for sustainability economics. The capability approach is however an incomplete framework, in the sense that it does not possess a theory of socio-economic processes. The capability approach provides instead a framework to describe and evaluate social and economic outcomes, focusing on freedom to choose, measured in terms of the expansion of the capability space. In fact, the capability approach is essentially concerned with what Baumgärtner and Quaas (2010) term as "ontology", that is, an enquiry on the nature of well-being, since it provides the categories that we can use to answer to the ontological question of "what is human well-being?"
The capability approach can bring a different perspective to the central issues within sustainability economics pointed out by Ballet, Bazin, Dubois and Mahieu (2011) when discussing the contribution of Baumgärtner and Quaas (2010, p.447), concerning: the satisfaction of individuals' needs and wants; and justice, between humans of present and future generations, and in human-nature relationships "over the long-term and inherently uncertain future." In fact, the capability perspective shows how these aspects are deeply interconnected. It is because future generations may face unpredictable and uncertain scenarios, in a context where the preferences and values of future generations may be different from ours, that the focus must be not only on contemporary needs and desires, but on real capabilities.

The capability approach provides thus a broader perspective of the first issue pointed out by Baumgärtner and Quaas (2010), namely human needs and desires, which enables us to accommodate the demands of the second issue pointed out in the definition of Baumgärtner and Quaas (2010), concerning intergenerational justice, and uncertainty.

But as an ontological exercise, the capability approach does not provide a substantive answer to these issues. It provides an answer to the ontological question of "what is human well-being", rather than to substantive issues within economic theory. This leads to a theoretical under-specification of the capability approach at a substantive level, which is a consequence of the fact that the capability approach is essentially an ontological exercise.

\section{References}

Anand, P., Hunter, G., Smith, R., 2005. Capabilities and well-being: evidence based on the Sen-Nussbaum approach to welfare. Social Indicators Research 74 (1), 9-55.

Archer, M., Bhaskar, R., Collier, A., Lawson, T., Norrie, A. (Eds.), 1998. Critical Realism: Essential Readings. Routledge, London.

Arrow, K.J., 1995. A Note on Freedom and Flexibility. In: Basu, K., Pattanaik, P.K., Suzumura, K. (Eds.), Choice, Welfare, and Development. A Festschrift in Honor of Amartya K. Sen. Oxford, Clarendon, pp. 7-16.

Baumgärtner, S., Quaas, M., 2010. What is sustainability economics? Ecological Economics 69 (3), 445-450.

Ballet, J., Bazin, D., Dubois, J.-L., Mahieu, F.R., 2011. A note on sustainability economics and the capability approach. Ecological Economics. doi:10.1016/j.ecolecon.2011.05.009.

Comim, F., 2003. Capability dynamics: the importance of time to capability assessments, paper presented at the 3rd conference on the capability approach, university of Pavia. Italy.

Kuklys, W., 2005. Amartya Sen's capability approach. Springer, Berlin.

Lawson, C., 2007a. Technology, Technological Determinism and the Transformational Model of Social Activity. In: Lawson, C., Latsis, J.S., Martins, N. (Eds.), Contributions to Social Ontology. Routledge, London.

Lawson, T., 2007b. An Orientation for a Green Economics? The International Journal of Green Economics 1 (3/4), 250-267.

Lawson, C., 2010. Technology and the extension of human capabilities. Journal for the Theory of Social Behaviour 40 (2), 207-223.

Leßmann, O., 2011. Freedom of Choice and Poverty Alleviation. Review of Social Economy. doi:10.1080/00346764.2011.577349.

Martins, N., 2006. Capabilities as Causal Powers. Cambridge Journal of Economics 30 (5), 671-685.

Martins, N., 2007. Ethics, Ontology and Capabilities. Review of Political Economy 19 (1), 37-53.

Martins, N., 2009. Sen's capability approach and post Keynesianism: similarities, distinctions and the cambridge tradition. Journal of Post Keynesian Economics 31 (4), 691-706.

Marx, K., 1959. Economic and Philosophical Manuscripts of 1844. Progress Publishers, Moscow. [1844]

Oosterlaken, I., 2011. Inserting technology in the relational ontology of Sen's capability approach. Journal of Human Development and Capabilities 12 (3), 425-432.

Pattanaik, P.K., Xu, Y., 1998. On preference and freedom. Theory and Decision 44 (2), $173-198$.

Qizilbash, M., 2008. In: Comim, Qizilbash, Alkire (Eds.), Amartya Sen's capability view: insightful sketch or distorted picture? 53-81.

Rawls, J., 1971. A Theory of Justice. The Belknap Press of Harvard University Press, Cambridge MA.

Robeyns, I., 2005. The capability approach: a theoretical survey. Journal of Human Development 6 (1), 93-117.

Sen, A.K., 1992. Inequality Reexamined. Oxford University Press, Oxford and New York.

Sen, A.K., 2009. The Idea of Justice. Allen Lane, London.

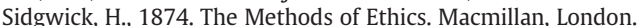

Smith, A., 2002. The Theory of Moral Sentiments. Cambridge University Press, Cambridge. [1759]

Smith, M.L., Seward, C., 2009. The relational ontology of Amartya Sen's capability approach: incorporating social and individual causes. Journal of Human Development and Capabilities 10 (2), 213-235. 